\title{
BMJ Open Role of maternal characteristics and epidural analgesia on caesarean section rate in groups 1 and 3 according to Robson's classification: a cohort study in an Italian university hospital setting
}

\author{
Stefania Triunfo, ${ }^{1}$ Sergio Ferrazzani, ${ }^{1}$ Gaetano Draisci, ${ }^{2}$ Bruno Antonio Zanfini, ${ }^{2}$ \\ Giovanni Scambia, ${ }^{1}$ Antonio Lanzone ${ }^{1}$
}

To cite: Triunfo S, Ferrazzani S, Draisci G, et al. Role of maternal characteristics and epidural analgesia on caesarean section rate in groups 1 and 3 according to Robson's classification: a cohort study in an Italian university hospital setting. BMJ Open 2018;8:e020011. doi:10.1136/ bmjopen-2017-020011

- Prepublication history for this paper is available online. To view these files, please visit the journal online (http://dx.doi org/10.1136/bmjopen-2017020011).

Received 13 0ctober 2017 Revised 6 February 2018 Accepted 12 February 2018

Check for updates

${ }^{1}$ Department of Obstetrics and Gynaecology, Fondazione Policlinico Universitario 'A. Gemelli', Catholic University of Sacred Heart, Rome, Italy ${ }^{2}$ Department of Anaesthesiology and Intensive Care, Fondazione Policlinico Universitario 'A. Gemelli', Catholic University of Sacred Heart, Rome, Italy

Correspondence to Dr Stefania Triunfo; stefania.triunfo@ policlinicogemelli.it

\section{ABSTRACT}

Objective To investigate the role of maternal characteristics and epidural analgesia (EA) on caesarean section (CS) rates in selected groups by using the Robson 10-Group Classification System (RTGCS).

Design Cohort study.

Setting Department of Obstetrics and Gynaecology, Fondazione Policlinico Universitario 'A. Gemelli', Rome, Italy.

Patients A total of 12098 deliveries in periods I (19981999) and II (2010-2011).

Main outcome measures CS rates in groups 1 and 3 of RTGCS.

Results In group 1, 1144 (20\%) patients were assigned to period I and 1302 (20.4\%) to period II, while in group $3,1587(27.8 \%)$ were assigned to period I and 1502 $(23.5 \%)$ to period II. CS rates were $16.4 \%$ and $23.1 \%$ in group 1 and $12.7 \%$ and $10.9 \%$ in group 3 in periods I and II, respectively. In group 1, significant and independent contributions to CS rate were provided by maternal age $(p=0.018$; OR 0.95 (95\% Cl 0.85 to 0.97$)$ ), body mass index (BMI) ( $p=0.022$; OR 0.89 (95\% Cl 0.85 to 0.91)) and $E A$ administration $(p=0.037$; OR $0.59(95 \% \mathrm{Cl} 0.43$ to $0.77))$. In group 3 , maternal age $(p<0.001 ;$ OR $0.93(95 \%$ $\mathrm{Cl} 0.89$ to 0.96$))$ and $\mathrm{BMI}(\mathrm{p}=0.023$; OR $0.98(95 \% \mathrm{Cl} 0.96$ to 0.99 )) were found to be significantly associated with CS. Conclusions RTGCS is an effective tool for analysing changes in obstetric care, allowing for the recognition of maternal age, BMI and EA administration in the strategic planning for mitigation of CS rates in selected groups.

\section{INTRODUCTION}

In the last few decades, a major public health problem has been the continuous increase of caesarean section (CS) rates, regardless of designation as a high-income or low-income country. ${ }^{1}$ Already in 1985 , WHO indicated that a CS rate greater than $10 \%-15 \%$ was not justified for any region of the world for optimal maternal and perinatal outcomes, ${ }^{2}$ while some recent revisions advocate an optimal global international CS rate of $19 \% .^{3}$
Strengths and limitations of this study

- This is the first study that explored the role of age and body mass index as maternal characteristics in selected groups of Robson 10-Group Classification System (RTGCS).

- No previous studies have assessed the role of administration of epidural analgesia according to RTGCS.

- The retrospective analysis could be considered as a study limitation.

- An exhaustive list of demographic characteristics was not considered in the analysis because it was not available.

Over the years, the need has been recognised to move away from the historical approach, based on CS indication, to simplicity of design, validity of purpose and ease of implementation at the healthcare facility level for clinicians and administrators. ${ }^{4}$ In two systematic reviews, ${ }^{56}$ the method chosen by the WHO as the most appropriate system to fulfil current international and local needs is characterised by a classification system of 10 groups of women admitted for delivery, segregated by five obstetric characteristics and named by its author as the Robson 10-Group Classification System (RTGCS) (table 1). ${ }^{7}$ Since its introduction, RTGCS has gained a wide acceptance, allowing the comparison of intrainstitutional and interinstitutional settings in the same nation and among different nations and promoting easy-to-implement strategies to reduce CS rates ${ }^{8-17}$ on its way to being well defined by WHO as the 'global standard'.

In the last few decades, some major changes in the demographics of the obstetric population have been observed. Among all, advanced 


\begin{tabular}{|c|c|}
\hline Group 1 & $\begin{array}{l}\text { Nullipara, } \geq 37 \text { weeks, single, cephalic } \\
\text { presentation, spontaneous labour. }\end{array}$ \\
\hline Group 2 & $\begin{array}{l}\text { Nullipara, } \geq 37 \text { weeks, single, cephalic } \\
\text { presentation, induced labour or CS before labour. }\end{array}$ \\
\hline Group 3 & $\begin{array}{l}\text { Multipara, single, no previous CS, } \geq 37 \text { weeks, } \\
\text { cephalic presentation, spontaneous labour. }\end{array}$ \\
\hline Group 4 & $\begin{array}{l}\text { Multipara, no previous CS, } \geq 37 \text { weeks, single, } \\
\text { cephalic presentation, induced labour or CS } \\
\text { before labour. }\end{array}$ \\
\hline Group 5 & $\begin{array}{l}\text { Multipara, previous CS, } \geq 37 \text { weeks, single, } \\
\text { cephalic presentation. }\end{array}$ \\
\hline Group 6 & Nullipara, single breech presentation. \\
\hline Group 7 & Multipara, single breech presentation. \\
\hline Group 8 & Multiple gestation (with or without previous CS). \\
\hline Group 9 & $\begin{array}{l}\text { Singleton pregnancy, oblique or transverse lies } \\
\text { (excluding breech, with or without previous CS). }\end{array}$ \\
\hline Group 10 & $\begin{array}{l}\text { Singleton, cephalic pregnancy, }<37 \text { weeks } \\
\text { (including previous CS). }\end{array}$ \\
\hline
\end{tabular}

CS, caesarean section.

maternal age at first birth has significantly contributed to rising rates of intrapartum primary caesarean delivery, most likely due to a biological basis. ${ }^{18}$ Second, abnormal nutritional status is a progressively common complication in reproductive-age women and an independent risk factor for feto-maternal complications and long-term risks in adult life. ${ }^{19}$ Third, the role of ethnicity appears critical, with increased risk among immigrant women of African origin, and lower CS rates in women from Eastern European countries and Maghreb when compared with native Western European women ${ }^{20}{ }^{21}$ probably due to the younger maternal age in immigrant mothers. ${ }^{15} 22$ Fourth, the assessment of maternal risk profiles and hospital acuity levels might be estimated as further independent risk factors. ${ }^{2324}$ Finally, during labour some interventions, such as the starting dose and increments of oxytocin (justified by presumed inefficient uterine action) or administration of epidural analgesia (EA) (widely used in reducing maternal pain) could increase the risk of instrumental delivery and/or CS. ${ }^{25}$ To the best of our knowledge, no previous research has been evaluated the latent benefits or adverse effects of EA on CS rate, as segregated by RTGCS.

The aim of the present study was to examine the changes in maternal characteristics and the effect of EA introduction on nulliparous and multiparous women in spontaneous labour by using the RTGCS in an Italian university hospital setting.

\section{MATERIALS AND METHODS}

The data for this study were extracted from a previous cohort, compiled with the aim of testing the clinical value of RTGCS to identify selected groups requiring interventions to reduce the CS rate at the Obstetrics and Gynaecology Department of 'A. Gemelli' University Hospital, Rome, Italy. ${ }^{16}$ The hospital is a tertiary referral centre with an average of 3100 deliveries per annum at the study time. Due to the nature of the study, research approval for the retrospective analysis was obtained without an ad hoc consent signed by patients.

\section{Study population}

At inclusion, all deliveries in 4years (1998, 1999, 2010, 2011) of a 13-year period were considered and categorised in agreement with RTGCS (figure 1). By using a

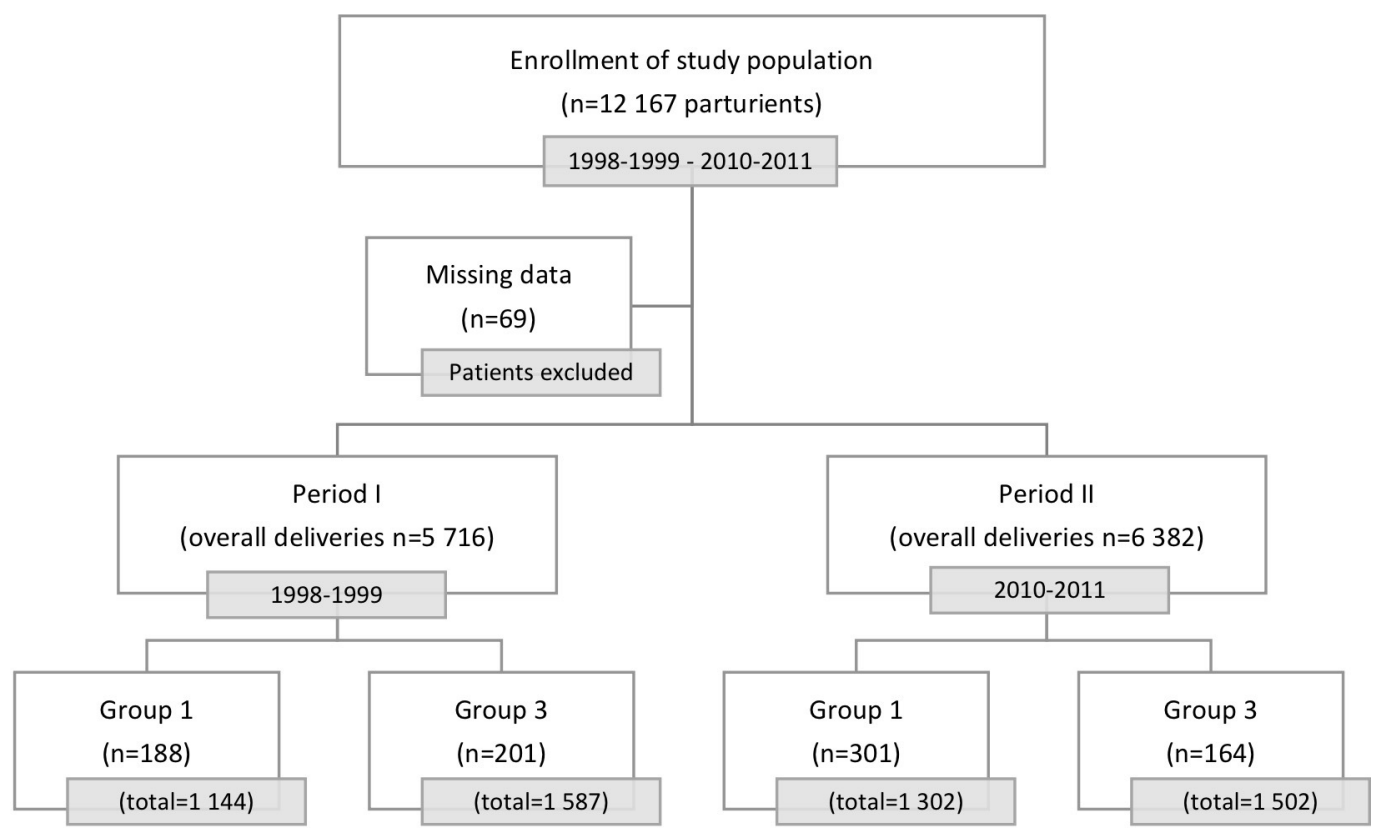

Figure 1 Flow chart of the obstetric study population examined in 4 years of a 13-year period, classified by the temporal criterion, such as period I (1998-1999) and period II (2010-2011). 
longitudinal comparative approach between period I (1998-1999) and period II (2010-2011), and in agreement with request for EA, satisfied after 2002 by an appropriate clinical protocol all pregnant women attributable to group 1 (nulliparous women with singleton cephalic full-term pregnancy in spontaneous labour) and group 3 (multiparous women with singleton cephalic full-term pregnancy in spontaneous labour) were examined.

Both an innovative computerised maternity database, designed as a tool for the hospital surveillance system and traditional paper birth registry were scrutinised. The following variables of interest were collected: maternal age, body mass index (BMI) at delivery, parity (nulliparous/multiparous), total number of previous $\mathrm{CS}$, number of fetuses (single/multiple), gestational age at delivery, birth presentation (cephalic/breech or transverse/ oblique lie), mode of delivery (vaginal delivery (VD), instrumental VD, CS), onset of labour (spontaneous/ induced), EA administration (yes/not).

\section{Clinical management}

All high-risk and low-risk pregnancies were formally assessed to ensure that the correct clinical management had been followed, according to local protocols. Labour induction was defined as the use of any medication (intravaginal or intracervical prostaglandin E2 gel, oxytocin). Vaginal operative delivery was accomplished only by Kiwi OmniCup ventouse, due to the impact on clinical practice of increased legal proceedings that discourage other options.

From 2002, an Epidural Outpatient Clinic at the Department of Anaesthesiology and Intensive Care and a 24-hour epidural service were available at the Delivery Unit. All women requesting analgesia for pain relief during labour were evaluated by an anaesthetist for suitability. Patients with absolute (ie, uncorrected hypovolaemia, coagulopathy, anticoagulant therapy, spina bifida occulta) or relative exclusion criteria (ie, anatomical deformities, some neurological disorders, sepsis) were ruled out from EA administration. After verifying blood test results and informing the women of EA-related risks (ie, accidental dural puncture, hypotension, inadequate analgesia, severe headache), a written informed consent was obtained from each patient. If the patient was receiving heparin therapy, the established prophylactic low molecular weight heparin (LMWH)-to-EA administration interval ( $\geq 12$ hours) and therapeutic LMWHto-EA administration interval ( $\geq 24$ hours) were required.

During labour, in the presence of a cervical dilatation of $\geq 3 \mathrm{~cm}$ and in the active phase of first-stage labour (established by partogram), maternal status (both blood pressure and temperature) and fetal well-being (the presence of $20 \mathrm{~min}$ of normal cardiotocography) were evaluated. In the absence of abnormalities, intravenous access by a 14-Gauge (G) or $16 \mathrm{G}$ cannula was positioned and a crystalloid infusion was started. The patient sat for skin preparation by aseptic technique, and an epidural catheter was placed at the L2-L3 or L3-L4 interspace.
Analgesia was established with an epidural administration of local anaesthetic and lipid-soluble opioid (ropivacaine $0,1 \%$ plus sufentanil $10 \mu \mathrm{g} / 20 \mathrm{~mL}$ ). Maternal blood pressure, fetal heart rate, pain scores and extent of sensory block were assessed at 5 min intervals for the first $15 \mathrm{~min}$, then every half hours. Analgesia was maintained with a manual 'top-up' technique (the anaesthetist administered an additional therapeutic bolus dose as analgesia began to wane, according to pain relative to the stage of labour and the extent of the sensory blockade), using increasing concentrations of ropivacaine, up to $0.15 \%$ at complete dilation. If needed, existing analgesia was supplemented with $5 \mathrm{~mL}$ of lidocaine $2 \%$ during the second stage of labour.

\section{Statistical analysis}

Normal distributions were assured by the Shapiro-Wilk test. The Student's t-test for independent samples, the Mann-Whitney U test, Pearson's $\mathrm{X}^{2}$ or Fisher's exact test were used to analyse collected data, as appropriate. Multivariate analysis was performed as well, and the contributions of maternal age, BMI and EA administration to CS rate for groups 1 and 3 were assessed by stepwise logistic regression. IBM SPSS V.23.0 and R V.2.15.1 (The R Foundation for Statistical Computing) with package V.1.7.2 software were used for statistical analyses. A $p<0.05$ was established as statistically significant.

\section{RESULTS}

By using a temporal criterion, a total of 12167 deliveries in 4 years of a 13-year period were segregated into period I (1998-1999) and period II (2010-2011), as detailed in the enrolment flowchart (figure 1). Missing information was observed in 69 patients, leaving 12908 patients for analysis. Among them, 1144 (20\%) pregnant women were categorised in group 1 and 1587 (27.8\%) in group 3 in period I, while 1302 (20.4\%) were categorised in group 1 and 1502 (23.5\%) in group 3 in period II.

The proportion of deliveries, number of CS, relative size and CS rate in each Robson Group in periods I and II are detailed in table 2. Baseline demographics of groups 1 and 3 are summarised in table 3 , showing statistically significant differences in both biennia and reflecting the overall trend in the study population. Delivery information is also itemised in figure 2, demonstrating a general rising CS birth rate from 38.7 to 43.7 per 100 births $(\mathrm{p}<0.001)$ in association with a significant reduction of VD (59.7\% vs $53.7 \%$; $\mathrm{p}<0.001)$. The CS rate was $16.4 \%$ and $23.1 \%$ in group 1 and $12.7 \%$ and $10.9 \%$ in group 3, in period I and period II, respectively. After its introduction in routine clinical care (2002), EA was administered in 255/301 (84.7\%) patients of group 1 and 136/164 $(82.9 \%)$ patients of group 3 in period II.

By logistic regression, in group 1, significant and independent contributions to the CS were provided by maternal age ( $\mathrm{p}=0.018$; OR 0.95 (95\% CI 0.85 to 0.97$)$ ), BMI at delivery ( $\mathrm{p}=0.022$; OR 0.89 (95\% CI 0.85 to 0.91$)$ ) 
Table 2 Proportion of deliveries, number of CS, relative size and CS rate in each Robson group in periods I and II

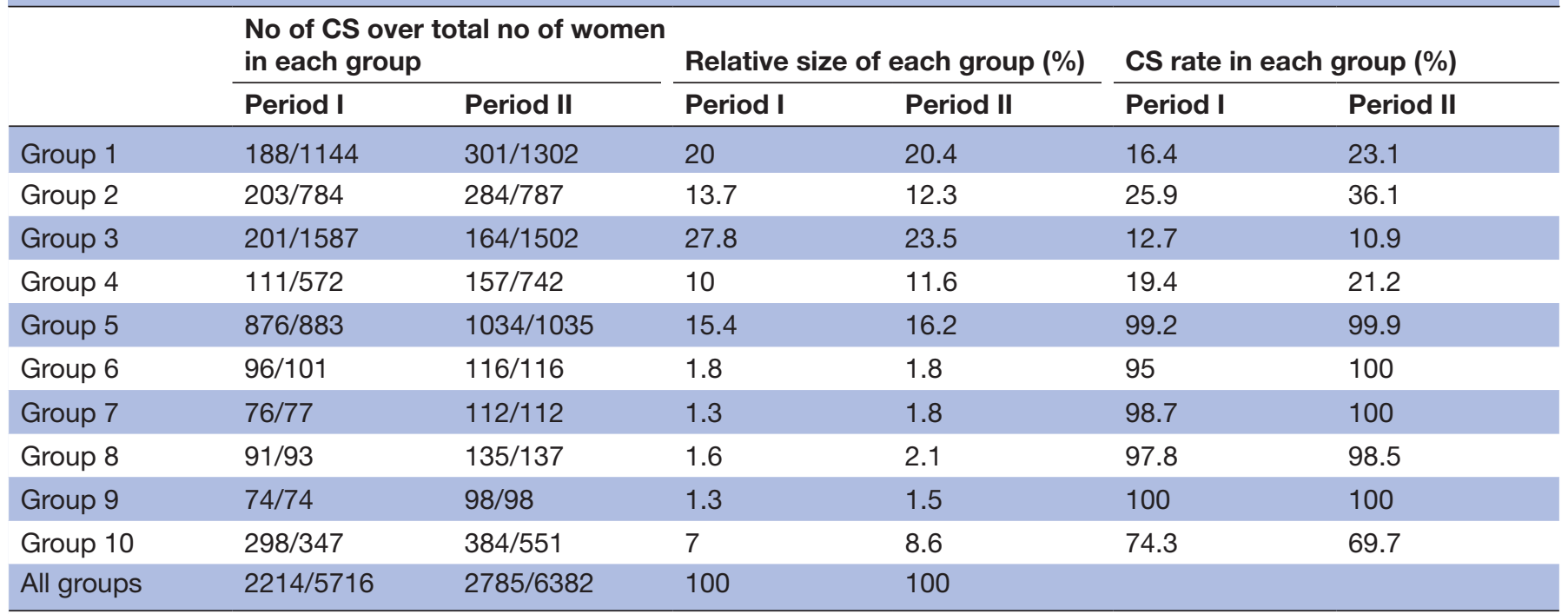

CS, caesarean section.

and EA administration ( $\mathrm{p}=0.037$; OR 0.59 (95\% CI 0.43 to 0.77$)$, while in group 3 by maternal age $(\mathrm{p}<0.001$; OR $0.93(95 \%$ CI 0.89 to 0.96$))$ and BMI at delivery $(\mathrm{p}=0.023$; OR 0.98 (95\% CI 0.96 to 0.99$)$ ), respectively (table 4$)$.

\section{DISCUSSION}

Our findings confirm the effectiveness of RTGCS as a clinical tool to analyse temporal changes in demographics and obstetric care. We found a significant association between CS rate and maternal age and BMI in both nulliparous (group 1) and multiparous (group 3) women with singleton cephalic full-term pregnancy in spontaneous labour. In contrast, EA administration played a role only in group 1.

This study is in line with the growing body of literature, based on RTGCS as an effective classification system to compare CS rates within specific subsets of obstetric populations, to settle various historical debates about the comparison of overall caesarean rates among different populations. ${ }^{9-16}$ Moving from the original philosophy of RTGCS, ${ }^{7}$ we and others have validated the classification system by longitudinal analysis, and we identified leading contributing groups requiring interventions (improvements in labour management and promotion of vaginal birth after caesarean (VBAC)). In our previous study, we found that in a 13-year period, nulliparous women in spontaneous or induced labour were resulted the second largest contributors to CS rate, after multiparous women with a previous $\mathrm{CS},{ }^{16}$ which addresses subsequent successful efforts in improving labour management protocol and promoting VBAC, as established in unpublished data.

Moving from the widespread consensus on the use of a priori Robson criteria, promoted also by the recent WHO statement for assessing, monitoring and comparing CS rates within healthcare facilities over time and between facilities, ${ }^{8}$ it should be acknowledged that a residual variability is accounted for by sociodemographic and clinical

Table 3 Maternal characteristics, EA administration and mode of delivery in the study population

\begin{tabular}{|c|c|c|c|c|c|}
\hline & \multicolumn{2}{|l|}{ Period I } & \multicolumn{2}{|l|}{ Period II } & \multirow[b]{2}{*}{ P values* } \\
\hline & $\begin{array}{l}\text { Group } 1 \\
(188 / 1144)\end{array}$ & $\begin{array}{l}\text { Group 3 } \\
(201 / 1587)\end{array}$ & $\begin{array}{l}\text { Group } 1 \\
(301 / 1302)\end{array}$ & $\begin{array}{l}\text { Group 3 } \\
\text { (164/1502) }\end{array}$ & \\
\hline Maternal age (years) & $27.6(4.1)$ & $33.1(3.7)$ & $31.2(4.9)$ & $35.5(4.8)$ & $<0.001 \dagger \ddagger$ \\
\hline BMI at delivery & $28.1(4.1)$ & $28.6(4.7)$ & $28.9(4.8)$ & $29.3(4.9)$ & $<0.001 \ddagger$ \\
\hline VD & 941 (82.3) & $1364(85.7)$ & $974(74.7)$ & $1299(86.5)$ & $<0.012 \ddagger$ \\
\hline OVD & $15(1.3)$ & $22(1.6)$ & $27(2.2)$ & $39(2.6)$ & 0.059 \\
\hline CS & 188 (16.4) & $201(12.7)$ & 301 (23.1) & 164 (10.9) & $<0.001 \dagger \ddagger$ \\
\hline
\end{tabular}

Data are given as mean (SD) or $\mathrm{n}(\%)$.

*Student's t-test for independent samples and Mann-Whitney $U$ test, Pearson's $\chi^{2}$ or Fisher's exact tests, as appropriate, with $p<0.05$ considered statistically significant.

†For group 1, period I versus period II.

fFor group 3, period I versus period II.

$\mathrm{BMI}$, body mass index; CS, caesarean section; EA, epidural analgesia; OVD, operative vaginal delivery; VD, vaginal delivery. 


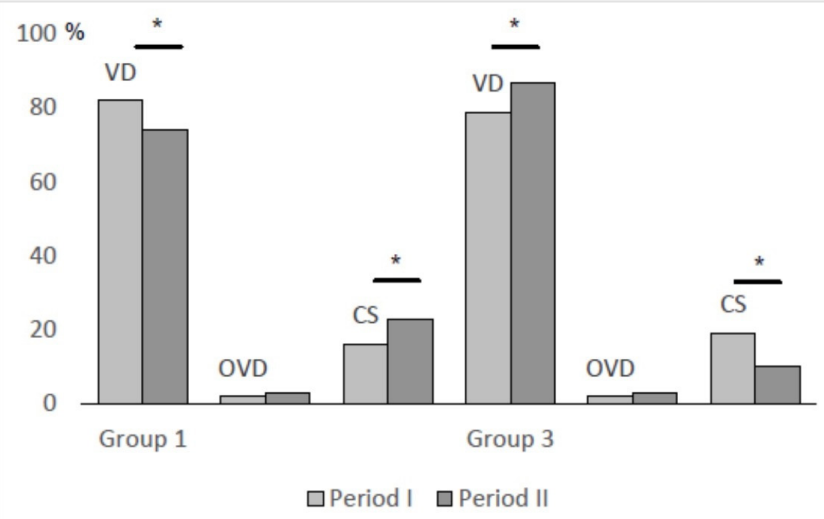

Figure 2 Mode of delivery in the study population, categorised in groups 1 and 3 and periods I and II, respectively. CS, caesarean section; OVD, operative vaginal delivery; VD, vaginal delivery. ${ }^{*} \mathrm{P}$ value $<0.05$

confounders. In their study population including 64 423 deliveries in Emilia-Romagna, Colais et al reported the significant impact of clinical and demographic confounders (including maternal age, comorbidity, assisted fecundation, fetal anomalies and intrauterine growth disorders) by two risk-adjustment models (only RTGCS as adjustment factor vs additional baseline and medical confounders) in groups 1 and $3 .{ }^{14}$ In a Canadian setting, Janoudi et al evaluated 134088 patients in different age intervals (20-34, 35-40 and >40 years) and found increased rates of CS in the top three Robson Groups in the presence of rising maternal age, associated with one or more additional factors (ie, previous CS, primiparity, assisted reproductive technology, chronic hypertension, gestational diabetes, diabetes mellitus and pre-eclampsia), suggesting the need for individual care providers to reduce CS risk, and to start from a common point, such as RTGCS, for more detailed analysis. ${ }^{26}$ Our results are in line with previous research. Indisputably, in older women, surgical interventions during labour by health providers might be influenced by an excess risk of prolonged labour, fetal distress, intrapartum CS and operative VDs, with risks for mother and child, and

Table 4 Logistic regression for evaluating associations between selected variables and CS in study groups

\begin{tabular}{lll}
\hline & P values & OR $(\mathbf{9 5 \%} \mathbf{C l})$ \\
\hline Group 1 & & \\
Maternal age & 0.018 & $0.95(0.85$ to 0.97$)$ \\
BMl at delivery & 0.022 & $0.89(0.85$ to 0.91$)$ \\
EA administration & 0.037 & $0.59(0.43$ to 0.77$)$ \\
Group 3 & \\
Maternal age & $<0.001$ & $0.93(0.89$ to 0.96$)$ \\
BMl at delivery & 0.023 & $0.98(0.96$ to 0.99$)$ \\
\hline EA administration & 0.810 & $0.99(0.97$ to 1.05$)$ \\
\hline
\end{tabular}

BMI, body mass index; CS, caesarean section; EA, epidural administration. supplementary economic costs to society. We found that maternal age is an independent variable for both nulliparous and multiparous women, and therefore irrespective of their obstetric history, while reflecting the worldwide delay in childbirth in the last decades. These findings could also be seen as a potential bias in comparing groups 1 and 3 from different hospitals. ${ }^{24}$ Consequently, it seems reasonable to add maternal age (as an absolute value or divided into intervals) in a classification system, as it has been included in the development of a global reference for benchmarking CS rates (named 'C-Model') and can generate an individualised reference rate for CS for groups of health facilities based on over 10 million women from multicountry populations. ${ }^{23}$

Another overarching phenomenon of the last few decades is represented by the growing prevalence of abnormal nutritional status in both developed and low/ middle-income countries, and, as the reproductive age of women is a part of this trend, the effects of maternal obesity on the pregnancy, including higher risk of CS, should be addressed. Already in previous studies designed to explore the contribution of abnormal BMI at birth to CS rate, a strong association has been pronounced and more recently confirmed using RTGCS, especially in spontaneous deliveries. ${ }^{14}{ }^{24}$ In agreement with previous investigations, our study confirms a wide-reaching tendency towards rising BMI in women of childbirth age. In a recent systematic review to gather the experience of RTGCS users, Betrán et al reported pros and cons, focusing attention on the absence of maternal factors that significantly influence CS rates, such as pre-existing abnormal BMI or excessive gestational weight gain, suggesting the necessity to account for them in additional statistical methods. ${ }^{6}$

Dissimilar to preceding investigations, an original aspect of our study is represented by the impact of pharmacological interventions for labour pain control on CS rate. To date, multiple observational studies have described an association between neuraxial (epidural, spinal or combined spinal-epidural) labour analgesia and caesarean delivery, but no full agreement is reported in systematic reviews and meta-analyses. ${ }^{25} 27$ This occurred with a previous Cochrane meta-analysis, conclusive for no statistically significant impact on CS risk, but only when considered with the limitations of substantial non-compliance and some concerns about external validity of some trials for contemporary maternity populations. In our population, we found a significant association between CS and EA administration only in nulliparous women. To interpret these results appropriately, we could speculate that, even accepting the relationship between labour analgesia and a longer second stage of labour, with a subsequent increased risk of CS, other obstetric factors, such as changes in physician behaviour, or non-medical risk factors could interfere with the final decision-making process. Medical assistance with delivery is undoubtedly influenced by a climate characterised by an alarming increase in the number of claims for compensation brought by patients who believe that the care they receive 
is inadequate, producing an overall declining confidence in medical practice, and by delayed and/or unique motherhood.

Of interest, although not statistically significant, are the findings in multiparous women. Over time, a reduction in CS rates has been observed in association with the use of pain control, accompanied by a raised (spontaneous or instrumental) VD rate. We could speculate that satisfactory pain relief might promote a reduction in CS by maternal request during labour, generating a collaborative behaviour between medical staff, midwives and the delivering women. Further research, in the form of randomised controlled trials, on the role played by EA administration alone is warranted before including it in any classification system to mitigate CS rate.

In terms of the generalisability, our research findings can be applied to settings other than in which we obtained them. The validation is conceivable because the changes in both demographics and clinical care have worldwide been recorded or performed in obstetric population.

The present study presents both strengths and limitations. This is the first investigation designed to evaluate the link between CS rates and one of the most common intrapartum interventions (EA administration) using RTGCS as well as some of the most relevant maternal characteristics that have changed over time. Additionally, we focused the analysis on selected RTGCS groups (1 and $3)$, those most in need of detailed definition and target interventions. However, we acknowledge that due to the nature of the study (retrospective), we did not account for a few clinical variables previously known to be associated with higher CS rates, because they were not available in our sources.

In conclusion, RTGCS permits the easy identification of the leading contributing groups to CS increases, and confirmation of the impact of some demographic changes on mode of delivery. In a prospective view, an ad hoc combination of characteristics and/or intrapartum interventions should be weighed to describe an individualised risk for $\mathrm{CS}$, built on the pre-existing clinical obstetric characteristics that form the base of the Robson classification.

Contributors Each author listed on the manuscript saw and approved the submission of this version of the manuscript and took full responsibility for the manuscript. There is not anyone else who fulfils the criteria that has been excluded as an author. ST gave substantial contributions to the conception and design of the work and to the interpretation of data. She was responsible for the acquisition of data. She wrote the first draft of the work and approved the final revised version. $\mathrm{SF}, \mathrm{GD}, \mathrm{ABZ}$ and GS gave substantial contributions to the design of the work, were responsible for the analysis of data and collaborated to their interpretation. They revisited the work critically and approved the final revised version. AL gave substantial contributions to the conception; he was responsible for the analysis of data and the interpretation of data. He revisited the work critically and approved the final revised version. All authors agree to be accountable for all aspects of the work in ensuring that questions related to the accuracy or integrity of any part of the work are appropriately investigated and resolved.

Funding This research received no specific grant from any funding agency in the public, commercial or not-for-profit sector.

Competing interests None declared.
Patient consent Not required.

Ethics approval Local Institutional Board of the Catholic University.

Provenance and peer review Not commissioned; externally peer reviewed.

Data sharing statement № additional data are available.

Open Access This is an Open Access article distributed in accordance with the Creative Commons Attribution Non Commercial (CC BY-NC 4.0) license, which permits others to distribute, remix, adapt, build upon this work non-commercially, and license their derivative works on different terms, provided the original work is properly cited and the use is non-commercial. See: http://creativecommons.org/ licenses/by-nc/4.0/

(c) Article author(s) (or their employer(s) unless otherwise stated in the text of the article) 2018. All rights reserved. No commercial use is permitted unless otherwise expressly granted.

\section{REFERENCES}

1. Betrán AP, Merialdi M, Lauer JA, et al. Rates of caesarean section: analysis of global, regional and national estimates. Paediatr Perinat Epidemiol 2007;21:98-113.

2. World Health Organization. Appropriate technology for birth. Lancet 1985;2:436-7.

3. Molina G, Weiser TG, Lipsitz SR, et al. Relationship between cesarean delivery rate and maternal and neonatal mortality. JAMA 2015;314:2263-70.

4. World Health Organization. WHO statement on caesarean section rates. Geneva: World Health Organization.

5. Torloni MR, Betran AP, Souza JP, et al. Classifications for cesarean section: a systematic review. PLoS One 2011;6:e14566.

6. Betrán AP, Vindevoghel N, Souza JP, et al. A systematic review of the Robson classification for caesarean section: what works, doesn't work and how to improve it. PLoS One 2014;9:e97769.

7. Robson MS. Classification of caesarean sections. Fetal Matern Med Rev 2011;12:23-39.

8. Brennan DJ, Robson MS, Murphy M, et al. Comparative analysis of international cesarean delivery rates using 10-group classification identifies significant variation in spontaneous labor. Am J Obstet Gynecol 2009;201:308.e1-308.e8.

9. Brennan DJ, Murphy M, Robson MS, et al. The singleton, cephalic, nulliparous woman after 36 weeks of gestation: contribution to overall cesarean delivery rates. Obstet Gynecol 2011;117:273-9.

10. Chong C, Su LL, Biswas A. Changing trends of cesarean section births by the Robson Ten Group Classification in a tertiary teaching hospital. Acta Obstet Gynecol Scand 2012;91:1422-7.

11. Betrán AP, Gulmezoglu AM, Robson M, et al. WHO global survey on maternal and perinatal health in Latin America: classifying caesarean sections. Reprod Health 2009;6:1-8.

12. Scarella A, Chamy V, Sepúlveda M, et al. Medical audit using the ten group classification system and its impact on the cesarean section rate. Eur J Obstet Gynecol Reprod Biol 2011;154:136-40.

13. Ciriello $E$, Locatelli $A$, Incerti $M$, et al. Comparative analysis of cesarean delivery rates over a 10-year period in a single Institution using 10-class classification. J Matern Fetal Neonatal Med 2012;25:2717-20.

14. Colais P, Fantini MP, Fusco D, et al. Risk adjustment models for interhospital comparison of CS rates using Robson's ten group classification system and other socio-demographic and clinical variables. BMC Pregnancy Childbirth 2012;12:54-60.

15. Minsart AF, De Spiegelaere M, Englert $Y$, et al. Classification of cesarean sections among immigrants in Belgium. Acta Obstet Gynecol Scand 2013;92:204-9.

16. Triunfo S, Ferrazzani S, Lanzone A, et al. Identification of obstetric targets for reducing cesarean section rate using the Robson ten group classification in a tertiary level hospital. Eur J Obstet Gynecol Reprod Biol 2015;189:91-5.

17. Tapia V, Betran AP, Gonzales GF. Caesarean section in Peru: analysis of trends using the robson classification system. PLoS One 2016;11:e0148138.

18. Ogden CL, Carroll MD. Prevalence of obesity among children and adolescents: United States, trends 1963-1965 through 2007-2008. 2010 http://www.cdc.gov/nchs/data/hestat/obesity_child 07 08/ obesity_child_07_08.htm

19. Triunfo S, Lanzone A. Impact of overweight and obesity on obstetric outcomes. J Endocrinol Invest 2014;37:323-9.

20. Vangen S, Stoltenberg C, Skrondal A, et al. Cesarean section among immigrants in Norway. Acta Obstet Gynecol Scand 2000;79:553-8.

21. Río I, Castelló A, Barona C, et al. Caesarean section rates in immigrant and native women in Spain: the importance of 
geographical origin and type of hospital for delivery. Eur $\mathrm{J}$ Public Health 2010;20:524-9.

22. Walsh J, Mahony R, Armstrong F, et al. Ethnic variation between white European women in labour outcomes in a setting in which the management of labour is standardised-a healthy migrant effect? BJOG: An Inter J Obstet Gynaecol 2011;118:713-8.

23. Souza JP, Betran AP, Dumont A, et al. A global reference for caesarean section rates (C-Model): a multicountry cross-sectional study. BJOG 2016;123:427-36.

24. Gerli S, Favilli A, Franchini D, et al. Is the Robson's classification system burdened by obstetric pathologies, maternal characteristics and assistential levels in comparing hospitals cesarean rates? A regional analysis of class 1 and 3. J Matern Fetal Neonatal Med 2018;31:173-7.

25. Anim-Somuah M, Smyth R, Howell C. Epidural versus non-epidural or no analgesia in labour. Cochrane Database Syst Rev 2005:CD000331.

26. Janoudi G, Kelly S, Yasseen A, et al. Factors associated with increased rates of caesarean section in women of advanced maternal age. J Obstet Gynaecol Can 2015;37:517-26.

27. Jones L, Othman M, Dowswell T, et al. Pain management for women in labour: an overview of systematic reviews. Cochrane Database Syst Rev 2012;14:CD009234. 